\title{
STRATEGI KAMPANYE RIDWAN KAMIL DALAM MEDIA INSTAGRAM
}

\author{
Fadhilah Juwita Lestari, Shany Pebrianti, Aceng Ruhendi Syaifullah*
}

Prodi Linguistik, Sekolah Pasca Sarjana Universitas Pendidikan Indonesia

fadhilah.juwita@gmail.com,shanypebrianti@upi.edu, acengruhendisaifullah@upi.edu

\begin{abstract}
ABSTRAK
Suasana politik di beberapa daerah di Indonesia semakin memanas menjelang Pilkada tahun 2018, tak terkecuali di Jawa Barat. Berbagai cara pun dilakukan oleh semua pasangan calon Gubernur dan Wakil Gubernur demi meraih kemenangan. Tidak sedikit kampanye-kampanye hitam dan kata-kata tidak santun dilakukan untuk menjelek-jelekan pasangan calon lawan. Ridwan Kamil merupakan salah satu calon gubernur Jawa Barat yang memiliki elektabilitas yang cukup tinggi di Jawa Barat. Mengacu pada hal tersebut, peneliti tertarik untuk mengetahui strategi kampanye yang dilakukan oleh Ridwan Kamil ditinjau dari sudut pandang linguistik. Makalah ini akan membongkar strategi tindak tutur, kesantuan, dan propaganda kampanye Ridwan Kamil dalam caption instagram official pribadinya. Makalah ini menggunakan teori tindak tutur ilokusi dari Searle dan Austin untuk mengungkap jenis tuturan yang digunakan RK dalam berkampanye. Selanjutnya teori Leech digunakan untuk mengetahui strategi dan indikator kesantunan yang digunakan oleh RK. Yang terakhir adalah teori strategi propaganda yang digagas oleh Lee \& Lee digunakan untuk mengungkap strategi propaganda di balik tuturan RK. Hasil penelitian menunjukan bahwa strategi tindak tutur yang paling banyak digunakan adalah Assertif; strategi kesantunan yang banyak digunakan adalah maksim penghargaan dengan mayoritas skala kesantunan untung/rugi; dan strategi propaganda yang paling sering digunakan adalah glittering generality. Berdasarkan hasil penelitian, citra yang ingin dibangun oleh RK dalam kampanyenya di media Instagram adalah integritas yang tinggi, bijaksana, merakyat, dan bercita-cita luhur.
\end{abstract}

Kata Kunci: strategi tindak tutur, prinsip kesantunan, strategi propaganda, Ridwan Kamil, Instagram 


\section{PENDAHULUAN}

Menjelang Pilkada serentak yang akan berlangsung pada Bulan Juni 2018, kondisi perpolitikan di Indonesia semakin memanas. Begitu juga dengan Pilkada di Jawa Barat, Semua pasangan kandidat Cagub dan Cawagub bersaing sangat keras untuk menarik hati masyarakat dengan berbagai cara. Bahasa merupakan alat yang paling penting dalam melancarkan strategi politik, karena persuasi kandidat kepada masyarakat tidak akan tersampaikan tanpa bahasa. Strategi tindak tutur dan pola kesantunan berbahasa dalam berkampanye sangat menunjang pencitraan kandidat dalam menarik hati pemilih. Maka dari itu sangat menarik untuk menganalisis strategi kampanye kandidat pimpinan daerah dari sudut pandang linguistik, khususnya dengan menggunakan pendekatan pragmatik.

Media sosial adalah salah satu alat yang digunakan oleh semua calon pasangan kandidat untuk berkampanye. Cakupan akses yang luas dan keleluasaan mengunggah konten informasi, menjadi kelebihan utama dari media sosial sebagai sarana propaganda kampanye politik pasangan calon. Salah satu Kandidat Gubernur Jawa Barat yang sangat aktif di media sosial adalah Ridwan Kamil (RK).
Beliau dikenal sangat aktif dalam media sosial instagram, bahkan sebelum ikut bertanding dalam perebutan kursi Gubernur di Jawa Barat. Postingan foto dan caption yang relatif unik mengenai seputar Kota Bandung dan kegiatan beliau, mengundang berbagai respon netizen dalam kolom komentar. Terlebih kini akun instagram official RK @ridwankamil dipenuhi dengan postingan dan caption kampanye politik.

Ridwan Kamil merupakan salah satu kandidat Cagub yang memiliki elektabilitas yang cukup tinggi berdasarkan beberapa hasil lembaga survey, maka dari itu peneliti tertarik untuk menganalisis strategi tindak tutur dan kesantunan RK dalam berkampanye di akun istagram officialnya @ridwankamil. Lebih jauh lagi, peneliti ingin mengungkap ideologi dari strategi propaganda yang diterapkan oleh RK dibalik tuturannya tersebut.

\section{LANDASAN TEORI}

Makalah ini akan menggunakan pendekatan pragmatik kritis atau gabungan antara pragmatik dan wacana alisis kritis untuk membedah strategi kampanye RK dalam caption instagram pribadinya. Teori yang akan dipakai untuk mengetahui strategi tindak tutur RK 
adalah teori ilokusi yang dikemukakan oleh Searle. Kemudian, teori yang dipakai untuk menganalisis strategi kesantunan RK adalah Teori Maksim kesantunan dari Leech, yang disertai dengan indikator kesantunan untuk memperkuat analisis. Sedangkan teori Lee \& Lee, digunakan untuk mengungkap teknik propaganda yang merupakan ideologi dibalik tuturan RK. Berikut ini adalah penjelasannya:

\subsection{Analisis Wacana Kritis dan}

\section{Pragmatik}

Analisis wacana adalah upaya pengkajian satuan-satuan bahasa yang lebih luas dari sekedar klausa dan kalimat, namun mencakup percakapan dan wacana tulis (Junaiah \& Arifin, 2010: 106). Hal ini sejalan dengan apa yang dikemukakan oleh Paltridge bahwa analisis wacana berfokus pada pengetahuan mengenai bahasa diatas kata, klausa, frase, dan kalimat yang diperlukan untuk mensukseskan komunikasi (2006:2). Sedangkan analisis Wacana Kritis lebih menekankan kepada penggunaan bahasa bukan hanya sekedar pada aspek kebahasaannya saja, namun lebih dari itu dengan menyertakan konteks, dimana bahasa digunakan untuk praktek dan tujuan tertentu, termasuk di dalamnya praktek kekuasaan (Eriyanto, 2001:7).
Pragmatik dan AWK memiliki tujuan yang berbeda, meskipun samasama memiliki konteks sebagai ranah kajiannya. Pragmatik lebih mengarah pada hubungan situasional dalam konteks tuturan dari penutur terhadap mitra tutur antar personal (Subagyo, 2010:178-179), sedangkan AWK melibatkan konteks dalam latar belakang situasi, historis, kekuasaan, dan ideologi (Van Dijk, 1997; Fairclough dan Wodak, 1997). Meskipun demikian, kedua pendekatan tersebut dapat dipadukan dalam suatu penelitian multidisipliner, karena proses berbahasa tidak dapat dipisahkan dari ideologis penutur. Seperti yang dikemukakan oleh Van Dijk bahwa teks tidak lahir dari ruang hampa yang netral, namun dibentuk dari mental kognisi seseorang (1997)

\subsection{Jenis Tuturan Ilokusi}

Searle (1969), Austin (1962) dan Allan (2001), menyatakan bahwa tindak tutur terdiri dari tiga hal yaitu: 1) Tindak Lokusi adalah tindakan ketika penutur mengucapkan suatu tuturan yang bermakna dalam suatu bahasa 2) Tindak Ilokusi adalah isi pesan yang ingin disampaikan oleh penutur dan 3) perlokusi yaitu dampak yang ditimbulkan dari tuturan atau tindakan yang dipicu oleh tuturan. Searle membagi tindak tutur ilokusi menjadi beberapa kategori yakni: 
1. Asertif (Assertives), yakni tuturan yang mengikat penuturnya akan kebenaran tuturan yang diungkapkan, misalnya menyatakan, menuntut, mengakui, menunjukan, melaporkan, menyebutkan,

2. Direktif (Directives), yakni bentuk tuturan yang dimaksudkan untuk mempengaruhi mitra tutur agar melakukan tindakan yang dituturkannya, misalnya, memesan, memerintah, meminta, mengajak, memaksa, menagih, mendesak, memohon, menantang

3. Ekspresif (Expressives), adalah bentuk tuturan yang berfungsi untuk menyatakan atau mengungkapkan sikap psikologis penutur terhadap suatu keadaan, misalnya berterima kasih, memberi selamat, meminta maaf, menyalahkan, memuji, berbelasungkawa.

4. Komisif (Commissives), yakni tindak tutur yang mengikat penuturnya untuk melakukan sesuatu yang dituturkannya seperti bersumpah, berjanji, mengancam.

5. Deklarasi (Declarations), yaitu bentuk tuturan yang menghubungkan isi tuturan dengan kenyataan atau mendeklarasikan sesuatu, misalnya berpasrah membatalkan, memaafkan, menobatkan, memutuskan, mengizinkan, mengangkat.

\subsection{Prinsip Kesantunan}

Leech dalam Allan

(2008:31) mengatakan bahwa fenomena kesantunan adalah suatu konvensi untuk meminimalisir efek keterancaman wajah, dimana dapat berubah-ubah sesuai dengan situasi dan kondisi sosial masyarakat. Strategi kesantunan dalam berbicara berpegang pada beberapa kaidah atau maksim berbahasa. Rahardi (2005:59) menguraikan kategori maksim kesantunan Leech sebagai berikut:

1. Maksim Kebijaksanaan (Tact Maxim)

Prinsipnya adalah: kurangi kerugian orang lain, dan tambahi keuntungan orang lain. Maksud dari maksim diatas yaitu selalu mengurangi keuntungan dirinya sendiri dan memaksimalkan keuntungan pihak lain dalam kegiatan bertutur.

2. Maksim Kedermawanan (Generosity Maxim)

Prinsipnya adalah: kurangi keuntungan diri sendiri, dan tambahi pengorbanan diri sendiri. Maksud dari maksim diatas yaitu agar peserta tutur dapat menghormati mitra tuturnya, kemudian terciptalah komunikasi yang saling menghormati. 
FON ; Jurnal Pendidikan Bahasa dan Sastra Indonesia

Volume 13 Nomor 2 Tahun 2018

3. Maksim Penghargaan (Approbation Maxim)

antara pihak yang satu dengan pihak lainnya.

Prinsipnya adalah: kurangi cacian pada orang lain, dan tambahi pujian pada orang lain. Maksud dari maksim ini adalah agar tercipta saling menghargai satu sama lain.

4. Maksim Kesederhanaan (Modesty Maxim)

Prinsipnya adalah: kurangi pujian pada diri sendiri, dan tambahi cacian pada diri sendiri. Maksud maksim ini adalah, penutur dianggap santun ketika bersikap rendah hati dan tidak sombong.

5. Maksim Kesepakatan (Agreement Maxim)

Prinsipnya adalah: kurangi ketidaksesuaian antara diri sendiri dengan orang lain, dan tingkatkan persesuaian antara diri sendiri dan orang lain. Maksud dari maksim diatas yaitu agar para peserta tutur dapat saling membina kecocokan atau kesepakatan di dalam kegiatan bertutur.

6. Maksim Simpati (Sympathy Maxim)

Prinsipnya adalah: kurangi antipasti antara diri sendiri dengan orang lain, dan perbesar simpati antara diri sendiri dan orang lain. Maksud dari maksim diatas yaitu agar para peserta tutur dapat memaksimalkan sikap simpati

Skala Kesantunan menurut Leech (1983:123-126) adalah sebagai berikut:

1. Skala untung/rugi (cost-benefit scale) merujuk kepada besar kecilnya kerugian dan keuntungan yang diakibatkan oleh sebuah tindak tutur pada sebuah tuturan. Semakin tuturan tersebut merugikan diri penutur, akan semakin dianggap santunlah tuturan itu, demikian sebaliknya,

2. Skala pilihan (Optionality Scale) menunjuk kepada banyak atau sedikitnya pilihan yang disampaikan si penutur kepada si mitra tutur. Semakin tuturan memungkinkan penutur atau mitra tutur mementukan pilihan yang banyak dan leluasa, akan dianggap semakin santunlah tuturan itu. Sebaliknya apabila tuturan tersebut tidak memberikan kebebasan memilih bagi petutur maka tuturan tersebut akan dianggap tidak santun.

3. Skala ketidak langsungan (Indirectness Scale) mengacu pada langsung atau tidak langsungnya maksud sebuah tuturan. Semakin tuturan itu bersifat langsung akan dianggap semakin tidak santun. Demikian sebaliknya, semakin tidak langsung maksud sebuah tuturan, akan dianggap semakin sanutun. 
4. Skala keotoritasan (Authority Scale) dan kepentingan. Maka tugas wacana menunjuk kepada hubungan status analisis kritis adalah untuk mengungkap sosial antara penutur dan mitra tutur pandangan dan keyakinan sosial yang yang terlibat dalam tuturan. Semakin tersembunyi di balik ujaran (Van Dijk: jauh jarak peringkat sosial antara 1997:9). Lee \& Lee (1939) dalam buku penutur dengan mitra tutur, tuturan klasiknya The Fine Art of Propaganda: A yang digunakan akan cenderung Study of Father Coughlin's Speeches menjadi semakin santun. Sebaliknya, pertamakali mengagas tujuh semakin dekat jarak peringkat status teknik/strategi propaganda, yakni:

sosial diantara keduanya, akan 1. Name Calling adalah memberi cenderung semakin tidak santun.

5. Skala jarak sosial (Social Distance Scale) mengacu pada jarak hubungan sosial antara penutur dan mitra tutur yang terlibat dalam sebuah tuturan. Ada kecenderungan bahwa semakin dekat jarak hubungan sosial dia antara keduanya, akan menjadi semakin kurang santun. Sebaliknya, semakin jauh jarak hubungan sosial antara penutur dengan mitra tutur, akan semakin santun tuturan yang digunakan.

\subsection{Ideologi dan Strategi Propaganda}

Threadgold (1989) mengatakan bahwa teks tidak pernah bebas atau kosong dari ideologi maupun tujuan (Paltridge, 2010:45). Namun pada praktiknya ideologi tersebut tidak ditampilkan secara explisit di dalam text atau ujaran dikarenakan berbagai alasan julukan/label buruk pada seseorang, gagasan, orang, lembaga supaya masyarakat tidak menyukai atau menolaknya. Teknik ini biasanya digunakan dalam kampanye hitam dengan tujuan menjelek-jelekan lawan.

2. Glittering Generality adalah suatu teknik menghubungkan gagasanya dengan 'kata atau istilah yang berkonotasi baik' dengan tujuan untuk membuat masa menerima dan menyetujui sesuatu tanpa memeriksa bukti-bukti. Biasanya strategi ini dilakukan untuk mengesankan hal yang dipropagandakan sebagai kebaikan dan kebijaksanaan seseorang dengan tujuan luhur dan mulia. Misalnya produk makanan instan yang mencantumkan “dengan bahan-bahan alami pilihan” yang mengesankan makana tersebut aman dan sehat untuk dikonsumsi. 
3. Transfer adalah Teknik membawa otoritas dukungan dari sesuatu yang dihargai dan disanjung kepada sesuatu yang lain agar sesuatu yang lain itu lebih dapat diterima. Biasanya strategi ini digunakan dengan cara mendompleng pengaruh seseorang yang berwibawa atau tokoh di masyarakat, untuk menarik simpati masa.

4. Testimonial, adalah memberikan kesempatan bagi khalayak unuk berasumsi, menilai, dan berkomentar baik atau buruk mengenai gagasan yang dibuatnya dengan tujuan untuk menarik simpati masa.

5. Plain Folks, teknik ini digunakan oleh pembicara propaganda dalam upaya meyakinkan masyarakat bahwa gagasan yang dikemukakan bagus dan tepat, karena mereka adalah bagian dari rakyat.

6. Card Stacking adalah penggiringan opini publik mengenai gagasan yang dikemukakan dengan memberikan ilustrasi, fakta-fakta, dan logika agar dapat diterima oleh masyarakat. Strategi ini hanya mengemukakan gagasan, orang, program atau apapun dari sisi positifnya saja, tanpa memunculkan kelemahannya.
7. Bandwagon, teknik ini digunakan dalam rangka mempengaruhi masa untuk mengikuti apa yang digagas oleh pemberi propaganda dengan cara meyakinkan masa bahwa banyak orang lain di dalam komunitas kelompok masa tersebut telah mengikuti gagasannya.

\section{METODOLOGI PENELITIAN}

\section{DAN ANALISIS DATA}

Penelitian ini menggunakan metode kualitatif dengan cara menelaah objek secara rinci dan mendalam. Dalam pemaparannya, penelitian ini dijelaskan secara deskriptif tanpa menggunakan perhitungan statistik. Namun untuk lebih memperjelas pemahaman dan analisis, maka digunakan angka-angka sebagai persentase kategorisasi objek yang sedang dijelaskan. Meskipun dibantu dengan angka dan persentase, penjelasan mengenai permasalahan yang sedang diteliti tetap dipaparkan secara deskriptif.

Data diperoleh dari caption instagram RK dari akun istagram officialnya @Ridwankamil yang diambil secara acak dari periode bulan MaretApril. Data yang diambil adalah 12 data yang dinilai mewakili data-data lainnya yang hampir serupa. Meskipun dalam postingan kampanye RK berbentuk 
gambar yang disertai teks, dan caption sebagai penjelas foto tersebut, namun peneliti membatasi data yang dianalisis hanya captionnya saja.

\section{TEMUAN DAN DISKUSI}

\subsection{Temuan}

\section{Temuan 1}

Dari 28 tuturan yang diambil dari 12 caption dalam instagram RK, diperoleh data bahwa strategi tindak tutur yang digunakan oleh RK dalam berkampanye di media instagram adalah: assertif 21 tuturan (55\%), Komisif 8 tuturan (21\%), Ekspresif 7 tuturan (19\%), direktif 2 tuturan (5\%), dan tidak ditemukan jenis tuturan deklaratif.

Berdasarkan data yang diperoleh, dapat dilihat bahwa RK lebih banyak menggunakan tuturan assertif dalam caption kampanyenya di IG. Karakteristik tuturan assertif adalah mengikat penuturnya mengenai kebenaran tuturan yang diungkapkan. Maka kesan yang ingin ditimbulkan RK adalah memiliki integritas yang tinggi, karena apa yang dituturkannya merupakan fakta. RK lebih banyak melaporkan sesuatu yang ia kerjakan dan apa yang sedang ia lihat. Hal tersebut mengesankan bahwa apa yang dikatakan berdasarkan data, karena RK telah benar-benar meninjau secara langsung ke lapangan.

Jenis tidak tutur kedua yang banyak digunakan oleh RK adalah komisif, yakni berupa penawaran dan janji. Jenis tuturan komisif berupa janji dan tawaran merupakan jenis tuturan yang sangat lumrah ditemukan dalam iklan kampanye. Kemudian tuturan ekspresif yang banyak digunakan oleh RK untuk memberikan kesan menghargai dan bersimpati adalah ucapan terimakasih, memuji, mengucapkan selamat, dan mendoakan. Sedangkan ekspresi mengeluh diungkapkan oleh RK dengan tuturan yang mengandung rasa humor di dalamnya. Namun di dalam data yang diambil tidak ditemukan tindak tutur deklaratif. Hal ini dinilai wajar karena keabsyahan sebagian besar ujaran deklaratif hanya berlaku ketika diucapkan dengan waktu, tempat, dan syarat tertentu seperti deklarasi kemerdekaan, pengangkatan, dan pemecatan. Sedangkan fungsi tersebut kurang diperlukan dalam iklan kampanye.

Untuk lebih jelasnya dapat dilihat pada tabel di bawah ini: 
Tabel 1. Tindak tutur Ilokusi Dalam Caption IG official RK

\begin{tabular}{|c|c|c|c|c|}
\hline $\begin{array}{l}\mathrm{N} \\
\mathrm{O}\end{array}$ & $\begin{array}{l}\text { Jenis } \\
\text { Ilokusi }\end{array}$ & \multicolumn{2}{|r|}{ Temuan Kalimat } & Fungsi \\
\hline \multirow[t]{14}{*}{1.} & \multirow[t]{14}{*}{ Assertif } & 1 & $\begin{array}{l}\text { Hari ini, Kang Emil berkunjung ke wilayah } \\
\text { selatan Jawa Barat. Mulai dari Kota Banjar } \\
\text { sampai ke Kabupaten Pangandaran. }\end{array}$ & Melaporkan \\
\hline & & 2 & $\begin{array}{l}\text { Dua daerah baru di Jawa Barat, masih memulai } \\
\text { geliatnya untuk menjadi daerah maju. }\end{array}$ & Menyatakan \\
\hline & & 3 & $\begin{array}{l}\text { Contoh bagaimana pemekaran wilayah menjadi } \\
\text { salah satu solusi dari berbagai masalah. }\end{array}$ & Menyatakan \\
\hline & & 4 & Mengunjungi Kota tetangga hari ini, Cimahi. & Melaporkan \\
\hline & & 5 & $\begin{array}{l}\text { Sebagai salah satu daerah terdekat dengan Kota } \\
\text { Bandung, Kota Cimahi memiliki peran besar pada } \\
\text { hubungan kedua daerah. }\end{array}$ & Menyatakan \\
\hline & & 6 & $\begin{array}{l}\text { Bagi warga Cimahi juga pasti tau perubahan2 yg } \\
\text { sudah terjadi di kota bandung kan? }\end{array}$ & Menunjukan \\
\hline & & 7 & $\begin{array}{l}\text { Kembali berkunjung ke Kabupaten Bandung, } \\
\text { kang Emil mengawali kunjungan hari ini di } \\
\text { daerah Banjaran. }\end{array}$ & Melaporkan \\
\hline & & 8 & $\begin{array}{l}\text { Salah satu isu penting di wilayah ini adalah banjir } \\
\text { dan pemerataan pelayanan publik melaluin } \\
\text { pemekaran wilayah. }\end{array}$ & Menyatakan \\
\hline & & 9 & $\begin{array}{l}\text { Pariwisata menjadi potensi besar yang akan } \\
\text { menghasilkan dampak ekonomi jika dikelola } \\
\text { dengan baik. }\end{array}$ & Menyatakan \\
\hline & & 10 & menit closing debat semalam. & Melaporkan \\
\hline & & $\dot{1}$ & $\begin{array}{l}\text { - Seharian Kang Emil berinteraksi dengan } \\
\text { warga Purwakarta. Ke Pasar, danau, kampung } \\
\text { topi, pesantren dll. }\end{array}$ & Melaporkan \\
\hline & & 12 & $\begin{array}{l}\text { Pres rilis Pilgub Jabar versi POPULI hari ini. } \\
\text { Pasangan \#rindujabarjuara1 unggul } 41.8 \% \text {. }\end{array}$ & Menunjukan \\
\hline & & 13 & $\begin{array}{l}\text { Semakin paham apa-apa yang dibutuhkan warga } \\
\text { Purwakarta. }\end{array}$ & Menyatakan \\
\hline & & 14 & $\begin{array}{l}\text { Desa Gentur, Warung Kondang Cianjur, puluhan } \\
\text { rumah warganya mengerjakan kerajinan } \\
\text { lampu/wadah kaca berbahan frame kuningan. } \\
\text { mewakili semangat } 1 \text { Desa } 1 \text { Produk yang }\end{array}$ & Menunjukan \\
\hline
\end{tabular}




\begin{tabular}{|c|c|c|c|c|}
\hline & & & menjadi program \#rindujabarjuara1. & \\
\hline & & $\dot{\bullet}$ & $\begin{array}{l}\text { - } 100 \text { juta rupiah per bulan adalah } \\
\text { pendapatan dari } 1 \text { Ha tambak udang galah di } \\
\text { pesisir Cirebon ini. }\end{array}$ & Menunjukan \\
\hline & & 16 & $\begin{array}{l}\text { Mobil AVATAR \#rindujabarjuara1 selalu dinanti } \\
\text { karena datang menghibur warga di pelosok- } \\
\text { pelosok desa. Bisa nonton film, karaoke, foto } \\
\text { booth dll. }\end{array}$ & Menunjukan \\
\hline & & 17 & $\begin{array}{l}\text { Mimpi menciptakan budaya jalan kaki di Kota } \\
\text { Bandung, dilakukan Kang Emil dengan } \\
\text { menghadirkan jalur pedestrian yang nyaman. }\end{array}$ & Menunjukan \\
\hline & & 18 & $\begin{array}{l}\text { Sebuah mimpi sederhana dengan hasil luar biasa, } \\
\text { berjalan kaki dalam aktifitas keseharian } \\
\text { masyarakat akan menghasilkan masyarakat yang } \\
\text { tidak hanya sehat secara jasmani, juga secara } \\
\text { rohani karena timbulnya interaksi publik di ruang } \\
\text { terbuka. }\end{array}$ & Menyatakan \\
\hline & & 19 & $\begin{array}{l}\text { Hadirnya trotoar yang nyaman di sudut-sudut } \\
\text { Kota Bandung saat ini, adalah upaya dari } \\
\text { kekuasaan yang digunakan untuk kepentingan } \\
\text { masyarakat. }\end{array}$ & Menunjukan \\
\hline & & 20 & $\begin{array}{l}\text { Kang Emil Menghadiri Isra Miraj } 1439 \text { H di } \\
\text { Majelis Al Busyro Zaadul Muslim di Citayam } \\
\text { Bogor. }\end{array}$ & Melaporkan \\
\hline & & 21 & $\begin{array}{l}\text { Juga mendapat restu dan doa dari Al Habib Alwi } \\
\text { bin Abdurahman Assegaf, Al Habib Abubakar bin } \\
\text { Abdurahman Assegaf dan Al Habib Usman bin } \\
\text { Yahya. }\end{array}$ & Menunjukan \\
\hline 2. & Direktif & 1 & $\begin{array}{l}\text { Mari bantu ekonomi desa dengan banyak } \\
\text { memesan produknya ke warga Desa Gentur } \\
\text { Cianjur ini. Khususnya para interiordesigner } \\
\text { @yunijie@diananazir dkk tolong diberdayakan } \\
\text { industri rumahan ini, dengan banyak memesan ya. }\end{array}$ & Mengajak \\
\hline & & 2 & $\begin{array}{l}\text { Ayo pada semangat untuk para relawan dan para } \\
\text { pendukung. Kemenangan sudah dekat. }\end{array}$ & Mengajak \\
\hline
\end{tabular}




\begin{tabular}{|c|c|c|c|c|}
\hline 3. & Deklaratif & & & \\
\hline \multirow[t]{7}{*}{4.} & \multirow[t]{7}{*}{ Ekspresif } & 1 & $\begin{array}{l}\text { susahnya pidato jika diburu-buru dalam } 1 \text { menit. } \\
\text { Ngos-ngosan seperti dikejar hutang oleh debt } \\
\text { collector atau dikejar mantan yang masih ngarep } \\
\text { wae, jiga si eta (:) }\end{array}$ & Mengeluh \\
\hline & & 2 & Hatur Nuhun. & $\begin{array}{l}\text { Berterimakasi } \\
\mathrm{h}\end{array}$ \\
\hline & & 3 & $\begin{array}{l}\text { Menariknya generasi keduanya sudah melek } \\
\text { digital commerce, walau masih jualannya lewat } \\
\text { Instagram. }\end{array}$ & Memuji \\
\hline & & 4 & keren kan. & Memuji \\
\hline & & 5 & Hatur Nuhun. & $\begin{array}{l}\text { Berterimakasi } \\
\mathrm{h}\end{array}$ \\
\hline & & $\bullet$ & - $\quad$ Selamat Hari Buruh. & $\begin{array}{l}\text { Mengucapkan } \\
\text { selamat }\end{array}$ \\
\hline & & $\bullet$ & $\begin{array}{l}\text { - Saya doakan para buruh selalu sehat } \\
\text { bersemangat. Agar sejahtera \& selamat dunia } \\
\text { akherat. }\end{array}$ & Mendo’akan \\
\hline \multirow[t]{6}{*}{5.} & \multirow[t]{6}{*}{ Komisif } & 1 & $\begin{array}{l}\text { Ke daerah mana \#RINDU harus berkunjung di } \\
\text { Kota Banjar dan Kabupaten Pangandaran? }\end{array}$ & Menawarkan \\
\hline & & 2 & $\begin{array}{l}\text { Hidup berdampingan, dengan masalah dan potensi } \\
\text { yang ada di dalamnya, ke mana \#RINDU harus } \\
\text { berkunjung di Kota Cimahi? }\end{array}$ & Menawarkan \\
\hline & & 3 & $\begin{array}{l}\text { Apa kira2 program kota bandung yg baik juga } \\
\text { untuk di terapkan di Cimahi? }\end{array}$ & Menawarkan \\
\hline & & 4 & $\begin{array}{l}\text { Adakah permasalahan penting lain yg perlu di } \\
\text { atasi oleh kang emil jika menjadi gubernur } \\
\text { kedepan? Sampaikan di kolom komentar. }\end{array}$ & Menawarkan \\
\hline & & 5 & $\begin{array}{l}\text { Jika Ada usulan ke daerah mana lagi yang perlu } \\
\text { didatangi Kang Emil? Sampaikan juga di kolom } \\
\text { komentar. }\end{array}$ & Menawarkan \\
\hline & & $\bullet$ & $\begin{array}{l}\text { - "Aqua culture economy" ini akan jadi } \\
\text { prioritas program } \\
\text { ekonomi \#rindujabarjuara1 untuk warga pesisir } \\
\text { sebagai alternatif unggulan jika warga tidak }\end{array}$ & Menjanjikan \\
\hline
\end{tabular}




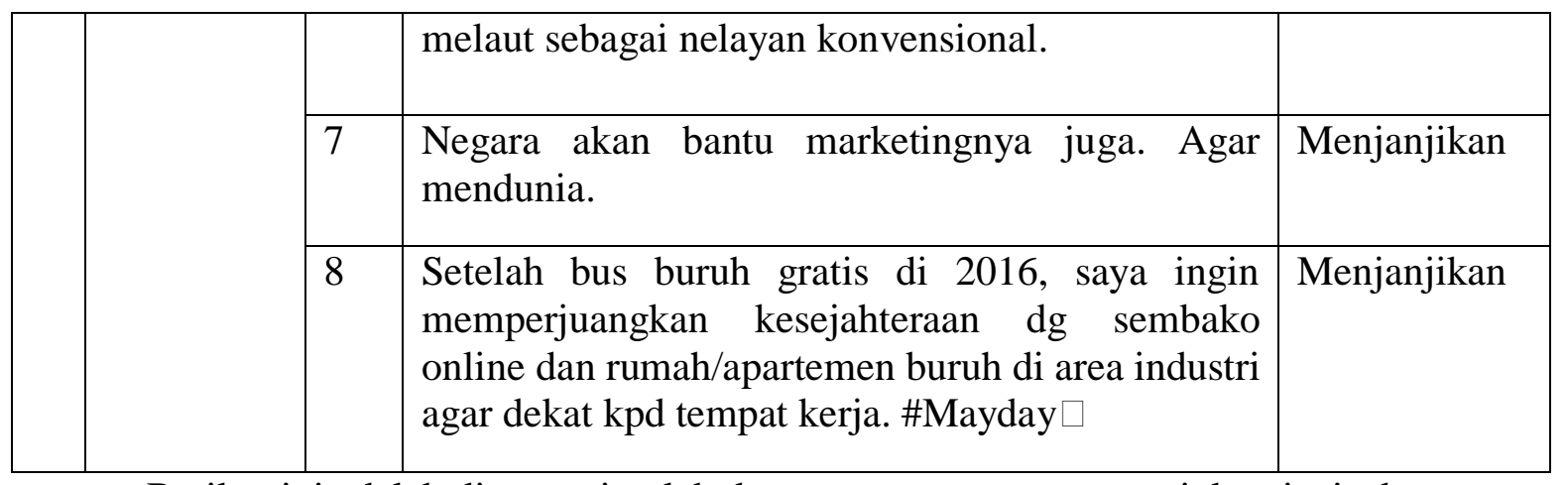

Berikut ini adalah diagram jumlah dan persentase yang menunjukan jenis dan jumlah strategi tindak tutur ilokusi yang digunakan oleh RK dalam berkampanye di media instagram.

Diagram 1. Persentase Jenis Tindak Tutur Kampanye RK

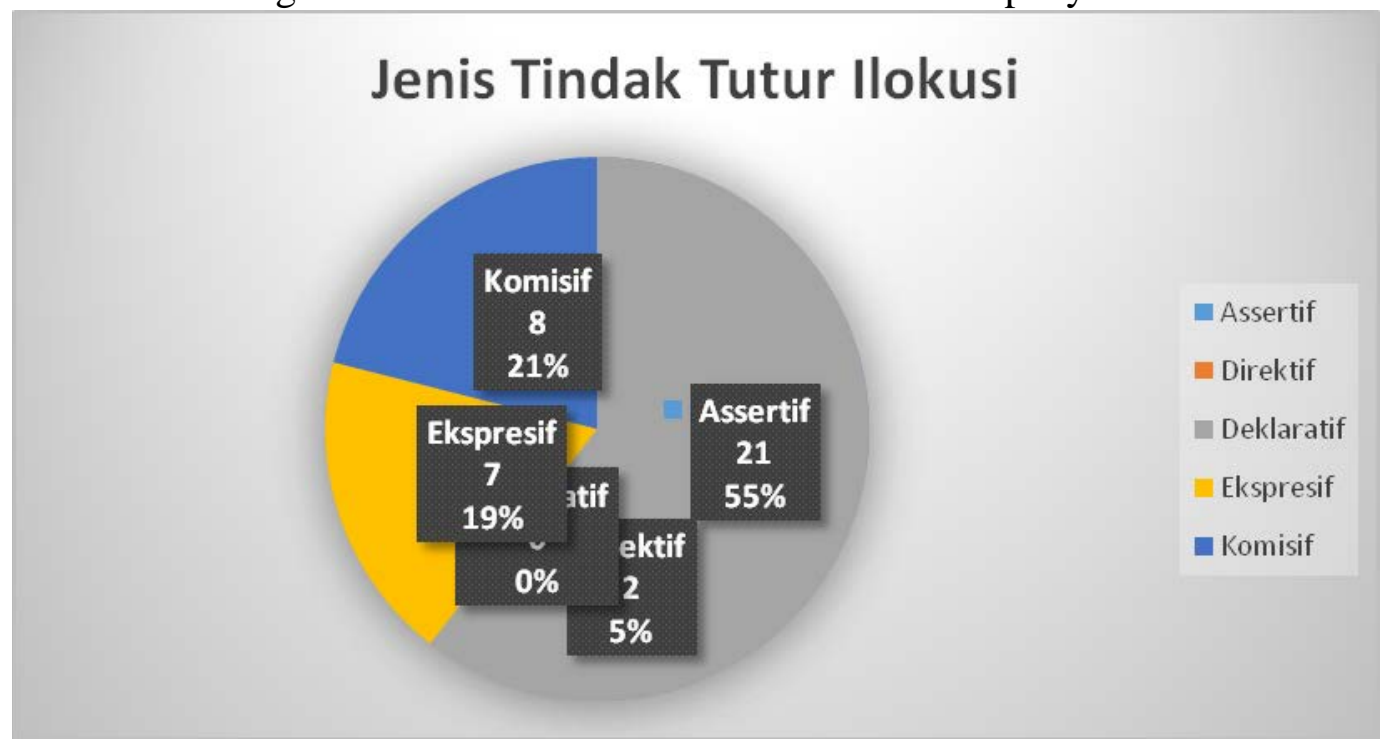

Temuan yang diperoleh dari hasil berterimakasih dan memuji masinganalisis data diatas adalah: jenis tuturan masing 2 tuturan (5\%), sedangkan dengan Assertif yang berfungsi untuk menunjukan fungsi mengeluh, mengucapkan selamat, menempati posisi mayoritas dengan dan mendoakan masing-masing berjumlah jumlah 8 tuturan (21\%), kemudian tuturan 1 tuturan (3\%). Dan yang terakhir jenis dengan fungsi meyatakan berjumlah 7 tuturan direktif dengan fungsi (18\%), dan tuturan dengan fungsi mengajak/menghimbau ditemukan 2 melaporkan berjumlah 6 tuturan (16\%). tuturan (5\%). Tabel 2. Berikut ini adalah Jenis tindak tutur komisif dengan fungsi klasifikasi fungsi tuturan yang digunakan menawarkan 5 tuturan (13\%), dan fungsi RK yang diperoleh dari hasil analisis data menjanjikan 3 tuturan (8\%). Jenis tindak di atas. tutur ekspresif dengan fungsi 
FON ; Jurnal Pendidikan Bahasa dan Sastra Indonesia

Volume 13 Nomor 2 Tahun 2018

Tabel 2. Klasifikasi Fungsi Tuturan dalam Kampanye RK

\begin{tabular}{|c|c|c|c|c|}
\hline $\mathrm{NO}$ & Jenis Tuturan & Fungsi & Jumlah & Persentase \\
\hline & \multirow[t]{3}{*}{ Assertif } & Menunjukan & 8 & $21 \%$ \\
\hline & & Menyatakan & 7 & $18 \%$ \\
\hline & & Melaporkan & 6 & $16 \%$ \\
\hline & \multirow[t]{2}{*}{ Komisif } & Menawarkan & 5 & $13 \%$ \\
\hline & & Menjanjikan & 3 & $8 \%$ \\
\hline & \multirow[t]{5}{*}{ Ekspresif } & Berterimakasih & 2 & $5 \%$ \\
\hline & & Memuji & 2 & $5 \%$ \\
\hline & & Mengeluh & 1 & $3 \%$ \\
\hline & & Mengucapkan Selamat & 1 & $3 \%$ \\
\hline & & Mendoakan & 1 & $3 \%$ \\
\hline & Direktif & Mengajak/Menghimbau & 2 & $5 \%$ \\
\hline & Deklaratif & & 0 & $0 \%$ \\
\hline
\end{tabular}

\section{Temuan 2}

Dari hasil analisis 20 data, 5\%.

ditemukan bahwa kategori maksim kesantunan yang paling banyak ditemukan adalah: maksim penghargaan 6 tuturan (30\%), kemudian maksim kebijaksanaan dan kesimpatian masing-masing 4 tuturan (20\%), maksim kedermawanan 3 tutuuran (15\%), maksim kesepakatan 2 tuturan $(10 \%)$, dan kesederhanaan/kerendahatian 1 tuturan

Strategi kesantunan yang digunakan RK dalam berkampanye lebih didominasi oleh maksim penghargaan, yakni katakata pujian yang selalu hadir diawal kalimat pembuka ketika RK mengunjungi suatu daerah. Kesan yang ingin ditimbulkan adalah sosok pemimpin yang menghargai dan mengayomi rakyatnya. 
Strategi tindak tutur yang terbanyak bagian dari rakyat. Selanjutnya adalah setelah maksim kebijaksanaan adalah penggunaan maksim kedermawanan, maksim kebijaksanaan dan maksim dimana mewakili citra pemimpin yang kesimpatian. Karena karakteristik maksim rela berkorban. Selain maksim kebijaksanaan adalah lebih mementingkan kesimpatian, penggunaan maksim keuntungan mitra tutur, dan maksim kesepakatan juga mewakili citra kesimpatian lebih menekankan pada pemimpin yang merakyat. Dan yang empati penutur terhadap kondisi mitra terakhir adalah maksim kesederhanaan tutur, maka kedua maksim tersebut yang mencerminkan kesantunan RK menimbulkan kesan mementingkan sebagai seorang pemimpin. kepentingan rakyat dan ikut menjadi

Tabel 2. Maksim Kesantunan dalam Caption IG RK

\begin{tabular}{|c|c|c|c|c|}
\hline $\mathrm{N}$ & Jenis Maksim & \multicolumn{2}{|r|}{ Temuan Kalimat } & \multirow{2}{*}{\begin{tabular}{l}
\multicolumn{1}{c}{ Skala } \\
\\
Skala \\
keuntungan/ \\
kerugian \& \\
Skala pilihan
\end{tabular}} \\
\hline \multirow[t]{4}{*}{1.} & \multirow[t]{4}{*}{ Kebijaksanaan } & 1 & $\begin{array}{l}\text { Ke daerah mana \#RINDU harus berkunjung di } \\
\text { Kota Banjar dan Kabupaten Pangandaran? }\end{array}$ & \\
\hline & & 2 & $\begin{array}{l}\text { Hidup berdampingan, dengan masalah dan } \\
\text { potensi yang ada di dalamnya, ke } \\
\text { mana \#RINDU harus berkunjung di Kota } \\
\text { Cimahi? }\end{array}$ & $\begin{array}{l}\text { Skala } \\
\text { keuntungan/ } \\
\text { kerugian \& } \\
\text { Skala pilihan }\end{array}$ \\
\hline & & 3 & $\begin{array}{l}\text { Adakah permasalahan penting lain yg perlu di } \\
\text { atasi oleh kang emil jika menjadi gubernur } \\
\text { kedepan? Sampaikan di kolom komentar. }\end{array}$ & $\begin{array}{l}\text { Skala } \\
\text { keuntungan/ } \\
\text { kerugian \& } \\
\text { Skala pilihan }\end{array}$ \\
\hline & & 4 & $\begin{array}{l}\text { Jika Ada usulan ke daerah mana lagi yang } \\
\text { perlu didatangi Kang Emil? Sampaikan juga di } \\
\text { kolom komentar. }\end{array}$ & $\begin{array}{l}\text { Skala } \\
\text { keuntungan/ } \\
\text { kerugian \& } \\
\text { Skala pilihan }\end{array}$ \\
\hline 2. & $\begin{array}{l}\text { Kedermawana } \\
\mathrm{n}\end{array}$ & 1 & $\begin{array}{l}\text { - Mari bantu ekonomi desa dengan } \\
\text { banyak memesan produknya ke warga Desa } \\
\text { Gentur Cianjur ini. Khususnya para interior } \\
\text { designer @yunijie@diananazir dkk tolong } \\
\text { diberdayakan industri rumahan ini, dengan } \\
\text { banyak memesan ya. }\end{array}$ & $\begin{array}{l}\text { Skala } \\
\text { keuntungan/ } \\
\text { kerugian }\end{array}$ \\
\hline
\end{tabular}




\begin{tabular}{|c|c|c|c|c|}
\hline & & 2 & $\begin{array}{l}\text { • "Aqua culture economy" ini akan jadi } \\
\text { prioritas program } \\
\text { ekonomi \#rindujabarjuara1 untuk warga pesisir } \\
\text { sebagai alternatif unggulan jika warga tidak } \\
\text { melaut sebagai nelayan konvensional. Negara } \\
\text { akan bantu marketingnya juga. Agar } \\
\text { mendunia. Hatur Nuhun. }\end{array}$ & $\begin{array}{l}\text { Skala } \\
\text { keuntungan/ } \\
\text { kerugian }\end{array}$ \\
\hline & & 3 & $\begin{array}{l}\text { - Setelah bus buruh gratis di 2016, saya } \\
\text { ingin memperjuangkan kesejahteraan dg } \\
\text { sembako online dan rumah/apartemen buruh di } \\
\text { area industri agar dekat kpd tempat kerja. }\end{array}$ & $\begin{array}{l}\text { Skala } \\
\text { keuntungan/ } \\
\text { kerugian }\end{array}$ \\
\hline 3. & Penghargaan & 1 & $\begin{array}{l}\text { Dua daerah baru di Jawa Barat, masih memulai } \\
\text { geliatnya untuk menjadi daerah maju. Contoh } \\
\text { bagaimana pemekaran wilayah menjadi salah } \\
\text { satu solusi dari berbagai masalah. }\end{array}$ & $\begin{array}{l}\text { Skala } \\
\text { ketidaklangsu } \\
\text { ngan }\end{array}$ \\
\hline & & - & $\begin{array}{l}\text { Sebagai salah satu daerah terdekat dengan Kota } \\
\text { Bandung, Kota Cimahi memiliki peran besar } \\
\text { pada hubungan kedua daerah. }\end{array}$ & $\begin{array}{l}\text { Skala } \\
\text { ketidaklangsu } \\
\text { ngan }\end{array}$ \\
\hline & & - & $\begin{array}{l}\text { - Pariwisata menjadi potensi besar yang } \\
\text { akan menghasilkan dampak ekonomi jika } \\
\text { dikelola dengan baik }\end{array}$ & $\begin{array}{l}\text { Skala } \\
\text { ketidaklangsu } \\
\text { ngan }\end{array}$ \\
\hline & & $\bullet$ & $\begin{array}{l}\text { Pres rilis Pilgub Jabar versi POPULI hari ini. } \\
\text { Pasangan \#rindujabarjuara1 unggul } 41.8 \% \text {. Ayo } \\
\text { pada semangat untuk para relawan dan para } \\
\text { pendukung. Kemenangan sudah dekat }\end{array}$ & $\begin{array}{l}\text { Skala } \\
\text { ketidaklangsu } \\
\text { ngan }\end{array}$ \\
\hline & & - & $\begin{array}{l}\text { Desa Gentur, Warung Kondang Cianjur, } \\
\text { puluhan rumah warganya mengerjakan } \\
\text { kerajinan lampu/wadah kaca berbahan frame } \\
\text { kuningan. mewakili semangat } 1 \text { Desa } 1 \text { Produk } \\
\text { yang menjadi program \#rindujabarjuara1. } \\
\text { Menariknya generasi keduanya sudah melek } \\
\text { digital commerce, walau masih jualannya } \\
\text { lewat Instagram. }\end{array}$ & $\begin{array}{l}\text { Skala } \\
\text { ketidaklangsu } \\
\text { ngan }\end{array}$ \\
\hline & & $\bullet$ & $\begin{array}{l}100 \text { juta rupiah per bulan adalah pendapatan } \\
\text { dari } 1 \text { Ha tambak udang galah di pesisir } \\
\text { Cirebon ini. keren kan. }\end{array}$ & $\begin{array}{l}\text { Skala } \\
\text { keuntungan/ } \\
\text { kerugian }\end{array}$ \\
\hline 4. & Kesepakatan & 1 & $\begin{array}{l}\text { Bagi warga Cimahi juga pasti tau perubahan2 } \\
\text { yg sudah terjadi di kota bandung kan? Apa } \\
\text { kira2 program kota bandung yg baik juga untuk }\end{array}$ & $\begin{array}{l}\text { Skala } \\
\text { keuntungan/ } \\
\text { kerugian \& }\end{array}$ \\
\hline
\end{tabular}




\begin{tabular}{|c|c|c|c|c|}
\hline & & & di terapkan di Cimahi? & Skala pilihan \\
\hline & & 2 & $\begin{array}{l}\text { Juga mendapat restu dan doa dari Al Habib } \\
\text { Alwi bin Abdurahman Assegaf, Al Habib } \\
\text { Abubakar bin Abdurahman Assegaf dan Al } \\
\text { Habib Usman bin Yahya. }\end{array}$ & $\begin{array}{l}\text { Skala jarak } \\
\text { sosial }\end{array}$ \\
\hline \multirow[t]{4}{*}{5.} & \multirow[t]{4}{*}{ Kesimpatian } & 1 & $\begin{array}{l}\text { Salah satu isu penting di wilayah ini adalah } \\
\text { banjir dan pemerataan pelayanan publik } \\
\text { melalui pemekaran wilayah. }\end{array}$ & $\begin{array}{l}\text { Skala } \\
\text { ketidaklangsu } \\
\text { ngan }\end{array}$ \\
\hline & & 2 & $\begin{array}{l}\text { - Seharian Kang Emil berinteraksi } \\
\text { dengan warga Purwakarta. Ke Pasar, danau, } \\
\text { kampung topi, pesantren dll. Semakin paham } \\
\text { apa-apa yang dibutuhkan warga Purwakarta. } \\
\text { Hatur Nuhun. }\end{array}$ & $\begin{array}{l}\text { Skala } \\
\text { ketidaklangsu } \\
\text { ngan }\end{array}$ \\
\hline & & 3 & $\begin{array}{l}\text { Selamat Hari Buruh. Saya doakan para buruh } \\
\text { selalu sehat bersemangat. Agar sejahtera \& } \\
\text { selamat dunia akherat. }\end{array}$ & $\begin{array}{l}\text { Skala } \\
\text { keuntungan/ } \\
\text { kerugian }\end{array}$ \\
\hline & & 4 & $\begin{array}{l}\text { Kang Emil Menghadiri Isra Miraj } 1439 \mathrm{H} \text { di } \\
\text { Majelis Al Busyro Zaadul Muslim di Citayam } \\
\text { Bogor. }\end{array}$ & $\begin{array}{l}\text { Skala jarak } \\
\text { sosial }\end{array}$ \\
\hline 6. & $\begin{array}{l}\text { Kesederhanaan } \\
\text { / Kerendahan } \\
\text { hati }\end{array}$ & 1 & $\begin{array}{l}\text { - menit closing debat semalam. susahnya } \\
\text { pidato jika diburu-buru dalam } 1 \text { menit. Ngos- } \\
\text { ngosan seperti dikejar hutang oleh debt } \\
\text { collector atau dikejar mantan yang masih } \\
\text { ngarep wae, jiga si eta (:) }\end{array}$ & $\begin{array}{l}\text { Skala } \\
\text { ketidaklangsu } \\
\text { ngan }\end{array}$ \\
\hline
\end{tabular}


FON ; Jurnal Pendidikan Bahasa dan Sastra Indonesia

Volume 13 Nomor 2 Tahun 2018

Berikut ini adalah diagram jumlah dan persentase strategi maksim kesantunan yang digunakan RK di media instagram:

Diagram 2. Persentase Maksim Kesantunan Kampanye RK

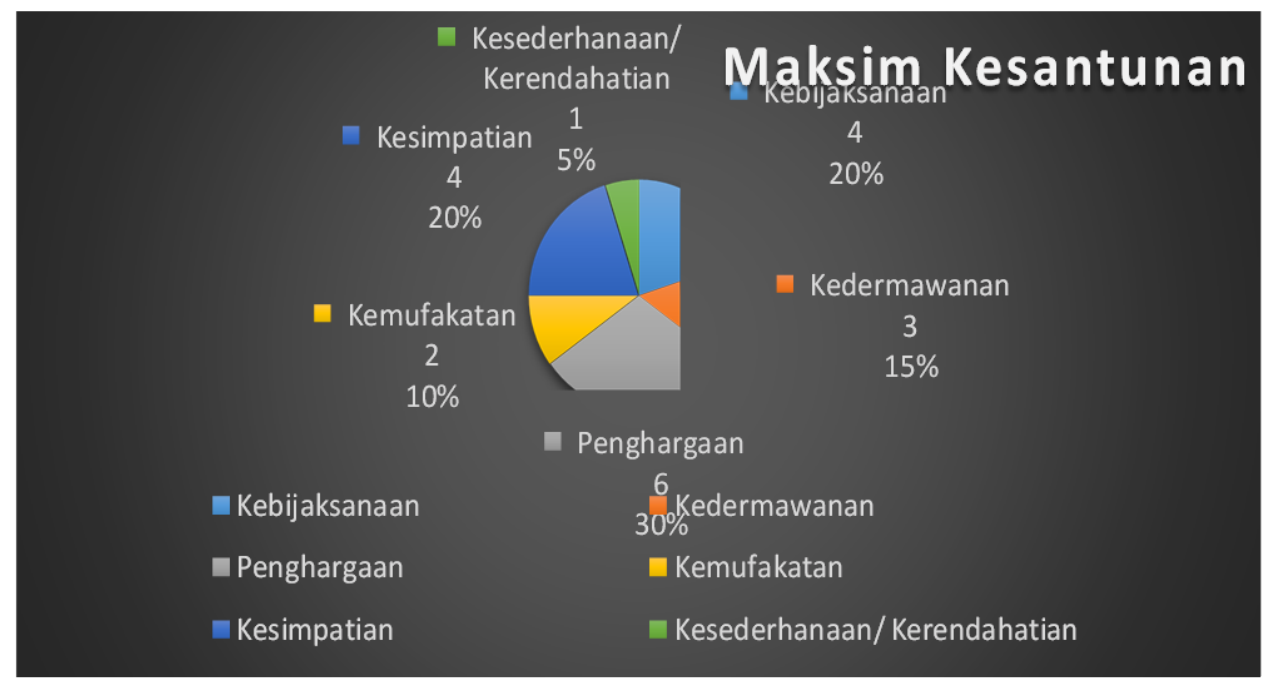

Selain jenis-jenis maksim mengindikasikan bahwa RK berusaha kesantunan, analisis data pada penelitian menempatkan posisi mitra tutur agar ini juga disertai dengan skala kesantunan selalu merasa lebih diuntungkan, dimana sebagai pendukung maksim kesantunan. mengesankan bahwa RK sebagai calon Dari hasil analisis data di atas diperoleh pemimpin Jawa Barat adalah pelayan data bahwa skala kesantunan yang paling rakyat, dan kepentingan rakyat merupakan tinggi penggunaannya adalah kategori prioritas utamanya. Kemudian skala ketidaklangsungan dengan jumlah 7 ketidaklangsungan juga cukup sering tuturan (40\%), kemudian skala digunakan oleh RK dalam bertutur. Jika untung/rugi 5 tuturan (25\%), gabungan melihat latarbelakang RK yang skala untung/rugi dan pilihan 5 tuturan merupakan orang sunda, tidak heran jika (25\%), skala jarak sosial 3 tuturan (10\%), RK sering menggunakan skala dan tidak ditemukan skala otoritas.

ketidaklangsungan, karena dalam kultur

Mayoritas skala kesantunan yang masyarakat sunda semakin tidak langsung digunakan oleh RK adalah skala maksud suatu tuturan maka semakin untung/rugi yakni 10 tuturan, meskipun 5 santun tuturan tersebut.

tuturannya adalah gabungan skala Skala pilihan yang digunakan oleh untung/rugi dengan skala pilihan. Hal ini RK selalu disandingkan dengan skala 
untung/rugi dalam penggunaannya, hal ini mengindikasikan bahwa RK memberikan pelayanan kepada rakyat dengan memberikan kebebasan dalam memilih atau dengan kata lain menjadi pemimpin yang demokratis. Selain itu, RK juga menggunakan skala jarak sosial dalam tuturannya, yakni ketika mendeskripsikan kegiatannya menghadiri undangan para ulama. RK menggunakan ragam bahasa yang lebih santun, dimana RK menempatkan diri seperti murid kepada

Tabel 4. Skala Kesantunan Kampanye RK

\begin{tabular}{|l|c|l|}
\hline \multicolumn{1}{|c|}{ Skala Kesantunan } & Jumlah Tuturan & \multicolumn{1}{c|}{ Persentase } \\
\hline Ketidaklangsungan & 8 & $40 \%$ \\
\hline Untung/rugi & 5 & $25 \%$ \\
\hline Untung/rugi \& pilihan & 5 & $25 \%$ \\
\hline Jarak sosial & 2 & $10 \%$ \\
\hline Pilihan & 0 & $0 \%$ \\
\hline Otoritas & 0 & $0 \%$ \\
\hline
\end{tabular}

\section{Temuan 3}

Dari hasil analisis ditemukan bahwa terdapat 6 strategi Propaganda yang menjadi maksud dibalik tuturan RK dalam caption instagramnya. Strategi propaganda yang paling banyak digunakan adalah strategi glittering generality 9 tuturan (43\%), kemudian disusul oleh testimonial 5 tuturan (24\%), bandwagon 2 tuturan (10\%), card stacking dan plain Folks gurunya. Sedangkan skala otoritas tidak ditemukan dalam tuturan RK. Hal ini mengindikasikan bahwa RK sangat menghindari kesan kesenjangan status sosial antara pemimpin dengan rakyatnya, karena kesan yang ingin dihadirkan RK dalam kampanyenya adalah pemimpin yang merakyat. Berikut ini dalah tabel yang menunjukan jumlah dan presentase skala kesantunan RK dalam iklan kampanyenya di media instagram: masing-masing 2 tuturan (9\%), transfer 1 tuturan (5\%), dan tidak ditemukan strategi name calling.

Strategi propaganda yang paling banyak digunakan oleh RK dalam iklan kampanyenya adalah glittering generality yaitu menggunakan istilah-istilah tertentu yang berkonotasi baik dengan tujuan untuk membuat masa menerima dan menyetujui gagasannya. RK ingin mengesankan program Rindu Jabar Juara 
yang ia promosikan sebagai kebaikan dan kebijaksanaan dengan tujuan luhur dan mulia. Strategi selanjutnya yang digunakan RK adalah testimonial yaitu dengan memberikan kesempatan bagi netizen untuk berasumsi, menilai, dan memberikan masukan mengenai gagasan yang dibuatnya dengan tujuan untuk menarik simpati masa.

Strategi bandwagon digunakan oleh RK untuk meyakinkan masyarakat bahwa telah banyak orang lain di dalam komunitas kelompok masyarakat tersebut yang telah mendukung RK. Kemudian RK juga menggunakan strategi plain folks untuk meyakinkan masyarakat bahwa program yang diajukan membawa dampak yang baik untuk rakyat, karena ia juga ada di pihak rakyat. Selain strategi plain folks,
RK juga menggunakan strategi card stacking untuk memperkuat program yang diusungnya dengan menggunakan ilustrasi, fakta-fakta, dan logika yang dapat diterima oleh masyarakat. Dan yang terakhir adalah strategi transfer, yakni RK menggunakan pengaruh para ulama yang dihargai dan disanjung untuk menarik simpati masa. Namun tidak ditemukan strategi Name Calling atau kampanye hitam dengan cara menjelek-jelekan lawan yang diimplementasikan oleh RK dalam kampanyenya. RK ingin mengesankan bahwa ia tetap sportif dalam bersaing dan merupakan hal yang tidak santun jika harus menjelek-jelekan kelemahan lawan. Untuk lebih jelasnya dapat dilihat pada tabel berikut:

Tabel. 5 Strategi Propaganda Kampanye RK dalam media IG

\begin{tabular}{|l|l|l|l|}
\hline No & \multicolumn{1}{|c|}{$\begin{array}{c}\text { Teknik } \\
\text { Propaganda }\end{array}$} & \multicolumn{2}{|c|}{ Temuan Kalimat } \\
\hline 1. & Name Calling & & \multicolumn{2}{|l|}{} \\
\hline \multicolumn{2}{|l|}{$\begin{array}{l}\text { Contoh bagaimana pemekaran wilayah } \\
\text { menjadi salah satu solusi dari berbagai masalah. }\end{array}$} \\
\hline 2. & $\begin{array}{l}\text { Glittering } \\
\text { Generality }\end{array}$ & 1 & $\begin{array}{l}\text { Sebagai salah satu daerah terdekat dengan } \\
\text { Kota Bandung, Kota Cimahi memiliki peran besar } \\
\text { pada hubungan kedua daerah. }\end{array}$ \\
\cline { 3 - 5 } & & 3 & $\begin{array}{l}\text { Pariwisata menjadi potensi besar yang akan } \\
\text { menghasilkan dampak ekonomi jika dikelola dengan } \\
\text { baik. }\end{array}$ \\
\hline & & 4 & $\begin{array}{l}\text { Semakin paham apa-apa yang dibutuhkan warga } \\
\text { Purwakarta. Hatur Nuhun. }\end{array}$ \\
\hline
\end{tabular}




\begin{tabular}{|c|c|c|c|}
\hline & & 5 & $\begin{array}{l}\text { Pres rilis Pilgub Jabar versi POPULI hari ini. } \\
\text { Pasangan \#rindujabarjuara1 unggul } 41.8 \% \text {. Ayo } \\
\text { pada semangat untuk para relawan dan para } \\
\text { pendukung. Kemenangan sudah dekat. }\end{array}$ \\
\hline & & 6 & $\begin{array}{l}\text { - Warung Kondang Cianjur, puluhan rumah } \\
\text { warganya mengerjakan kerajinan lampu/wadah kaca } \\
\text { berbahan frame kuningan. mewakili semangat } 1 \\
\text { Desa } 1 \text { Produk yang menjadi program } \\
\text { \#rindujabarjuara1. }\end{array}$ \\
\hline & & 7 & $\begin{array}{l}\text { - "Aqua culture economy" ini akan jadi } \\
\text { prioritas program ekonomi \#rindujabarjuara1 untuk } \\
\text { warga pesisir sebagai alternatif unggulan jika } \\
\text { warga tidak melaut sebagai nelayan konvensional. } \\
\text { Negara akan bantu marketingnya juga. Agar } \\
\text { mendunia. Hatur Nuhun. }\end{array}$ \\
\hline & & 8 & $\begin{array}{l}\text { Setelah bus buruh gratis di 2016, saya ingin } \\
\text { memperjuangkan kesejahteraan dg sembako online } \\
\text { dan rumah/apartemen buruh di area industri agar } \\
\text { dekat kpd tempat kerja. \#Mayday } \square\end{array}$ \\
\hline & & 9 & $\begin{array}{l}\text { Menariknya generasi keduanya sudah melek } \\
\text { digital commerce, walau masih jualannya lewat } \\
\text { Instagram. }\end{array}$ \\
\hline 3. & Transfer & 1 & $\begin{array}{l}\text { Kang Emil Menghadiri Isra Miraj } 1439 \mathrm{H} \text { di } \\
\text { Majelis Al Busyro Zaadul Muslim di Citayam Bogor. } \\
\text { Juga mendapat restu dan doa dari Al Habib Alwi } \\
\text { bin Abdurahman Assegaf, Al Habib Abubakar bin } \\
\text { Abdurahman Assegaf dan Al Habib Usman bin } \\
\text { Yahya. }\end{array}$ \\
\hline \multirow[t]{4}{*}{4.} & Testimonial & 1 & $\begin{array}{l}\text { Ke daerah mana \#RINDU harus berkunjung di } \\
\text { Kota Banjar dan Kabupaten Pangandaran? }\end{array}$ \\
\hline & & 2 & $\begin{array}{l}\text { Hidup berdampingan, dengan masalah dan potensi } \\
\text { yang ada di dalamnya, ke mana \#RINDU harus } \\
\text { berkunjung di Kota Cimahi? }\end{array}$ \\
\hline & & 3 & $\begin{array}{l}\text { Bagi warga Cimahi juga pasti tau perubahan2 yg } \\
\text { sudah terjadi di kota bandung kan? Apa kira } \\
\text { program kota bandung yg baik juga untuk di } \\
\text { terapkan di Cimahi? }\end{array}$ \\
\hline & & 4 & $\begin{array}{l}\text { Adakah permasalahan penting lain yg perlu di atasi } \\
\text { oleh kang emil jika menjadi gubernur kedepan? } \\
\text { Sampaikan di kolom komentar. }\end{array}$ \\
\hline
\end{tabular}




\begin{tabular}{|c|c|c|c|}
\hline & & 5 & $\begin{array}{l}\text { Jika Ada usulan ke daerah mana lagi yang perlu } \\
\text { didatangi Kang Emil? Sampaikan juga di kolom } \\
\text { komentar. }\end{array}$ \\
\hline \multirow[t]{2}{*}{5.} & Plain Folks & 1 & $\begin{array}{l}\text { - Seharian Kang Emil berinteraksi dengan } \\
\text { warga Purwakarta. Ke Pasar, danau, kampung topi, } \\
\text { pesantren dll. Semakin paham apa-apa yang } \\
\text { dibutuhkan warga Purwakarta. Hatur Nuhun. } \\
\text { selalu dinanti karena datang menghibur warga di } \\
\text { pelosok-pelosok desa. Bisa nonton film, karaoke, } \\
\text { foto booth dll. }\end{array}$ \\
\hline & & 2 & $\begin{array}{l}\text { Setelah bus buruh gratis di 2016, saya ingin } \\
\text { memperjuangkan kesejahteraan dg sembako online } \\
\text { dan rumah/apartemen buruh di area industri agar } \\
\text { dekat kpd tempat kerja. \#Mayday } \square\end{array}$ \\
\hline \multirow[t]{2}{*}{6.} & Card Stacking & 1 & $\begin{array}{l}\text { - Sebuah mimpi sederhana dengan hasil luar } \\
\text { biasa, berjalan kaki dalam aktifitas keseharian } \\
\text { masyarakat akan menghasilkan masyarakat yang } \\
\text { tidak hanya sehat secara jasmani, juga secara } \\
\text { rohani karena timbulnya interaksi publik di ruang } \\
\text { terbuka. }\end{array}$ \\
\hline & & 2 & $\begin{array}{l}\text { Hadirnya trotoar yang nyaman di sudut-sudut Kota } \\
\text { Bandung saat ini, adalah upaya dari kekuasaan } \\
\text { yang digunakan untuk kepentingan masyarakat. }\end{array}$ \\
\hline \multirow[t]{2}{*}{7.} & Bandwagon & 1 & $\begin{array}{l}\text { - Bagi warga Cimahi juga pasti tau } \\
\text { perubahan2 yg sudah terjadi di kota bandung kan? }\end{array}$ \\
\hline & & 2 & $\begin{array}{l}\text { Pres rilis Pilgub Jabar versi POPULI hari ini. } \\
\text { Pasangan \#rindujabarjuara1 unggul } 41.8 \% \text {. Ayo pada } \\
\text { semangat untuk para relawan dan para pendukung. } \\
\text { Kemenangan sudah dekat. }\end{array}$ \\
\hline
\end{tabular}


Berikut ini adalah diagram jumlah dan persentasi strategi propaganda yang digunakan oleh RK dalam kampanyenya di media Instagram

Diagram 3. Strategi Propaganda Kampanye RK dalam IG

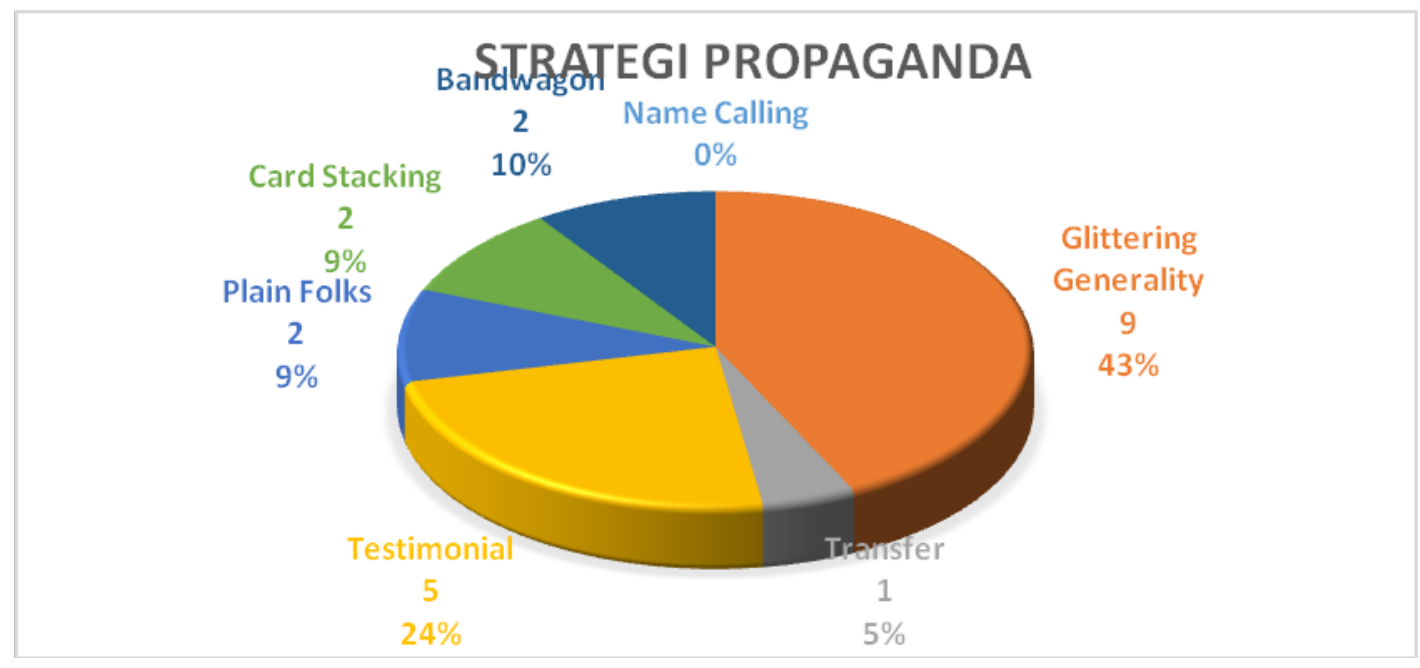

\subsection{Diskusi}

Penelitian ini diilhami oleh penelitian-penelitian sebelumnya yang menganalisis teks menggunakan pendekatan pragmatik dan/atau analisis wacana kritis. Subagyo (2010) dalam artikelnya yang berjudul Pragmatk Kritis: Paduan Pragmatik dengan Analisis Wacana Kritis mengemukakan bahwa sangat memungkinkan untuk melakukan penelitian pragmatik secara kritis. Karena ada keterkaitan yang kuat antara analisis pragmatik dalam konteks tuturan, dengan maksud tersembunyi dari tuturan dalam konteks wacana yang berupa ideologi. Selain itu di dalam artikel ini juga dibahas mengenai contoh penerapan pendekatan pragmatik kritis dalam penelitian. Meskipun pada dasarnya artikel ini bukan penelitian yang secara khusus dan mendalam mengupas suatu teks, namun artikel ini menjadi pijakan untuk penelitian yang memadukan pragmatik dengan analisis wacana kritis.

Rochmawati (2017) dalam artikelnya yang berjudul Pragmatic and Rhetorical Strategies in the EnglishWritten Jokes, meneliti strategi humor orang-orang yang ada di lingkugan Bone Regency. Beliau menggunakan pendekatan pragmatik untuk mengungkap pelanggaran maksim dalam humor tertulis, dan dipadukan dengan pendekatan wacana analisis untuk menganalisis strategi retorika yang digunakan dalam humor tersebut. Demikian juga dengan penelitian ini yang menggunakan pendekatan multi disiplin sebagai pisau 
FON ; Jurnal Pendidikan Bahasa dan Sastra Indonesia

Volume 13 Nomor 2 Tahun 2018

bedah untuk menganalisis objek Penelitian ini menggunakan teori penelitian. Pendekatan pragmatik tindak tutur ilokusi yang sama dengan digunakan untuk menganalisis strategi tindak tutur dan prinsip kesantunan yang digunakan oleh RK dalam berkampanye, sedangkan pendekatan AWK digunakan untuk membongkar maksud propaganda dari tuturan RK dalam caption instagramnya.

Hardini dalam artikelnya yang berjudul Analisis Pragmatik dalam Wacana Kampanye Politik Pemilihan Gubernur dan Wakil Gubernur Jawa Tengah Periode 2013-2018, menggunakan pendekatan pragmatik untuk mengungkap strategi tindak tutur, implikatur, dan maksud tujuan Paslon dalam iklan kampanye. Data penelitian tersebut diambil dari media baligo sedangkan penelitian ini menggunakan caption instagram sebagai data penelitian. Hasil penelitian menunjukan bahwa RK telah mentaati seluruh maksim kesantunan yang dikemukakan oleh Leech yaitu maksim kebijaksanaan, penghargaan, kesepakatan, kesederhanaan, kesimpatian, dan kedermawanan. Sedangkan dalam penelitian Hardini, ditemukan bahwa iklan kampanye Paslon banyak melanggar maksim kerjasama yang dikemukakan oleh Grice.

penelitian yang dilakukan oleh Septian yang berjudul Analisis Tindak Tutur Ilokusi dalam bahasa Iklan Kampanye Partai Politik pada Pemilu Legislatif tahun 2014 di Indonesia, yang berbeda adalah sumber data dan hasil temuan. Jika pada penelitiannya Septian menemukan bahwa tindak tutur ilokusi yang banyak digunakan oleh Caleg adalah tindak tutur ekspresif, sedangkan hasil temuan pada penelitian ini menujukan bahwa tindak tutur ilokusi yang banyak digunakan oleh RK adalah assertif. Dalam iklan kampanye di akun Instagramnya RK ingin mengesankan bahwa dirinya memang berbicara sesuai fakta, apa yang dikatakan memang benar telah dilakukan. Hal ini terlihat dari jenis tuturan assertif yang banyak digunakan adalah fungsi melaporkan, dimana ia melaporkan secara aktual bahwa dirinya saat itu sedang berada di suatu tempat yang ia kunjungi di Jawa Barat.

Sutanto menulis artikel yang berjudul Propaganda Politik Calon Presiden Republik Indonesia 2014 -2019 (Analisis Isi Berita Kampanye Pemilihan Presiden Tahun 2014 pada Harian Kompas Edisi 4 Juni sampai 5 Juli 2014), dengan tujuan untuk mengetahi pola dan 
strategi propaganda yang digunakan oleh calon presiden RI 2014-2019. Persamaan artikel tersebut dengan penelitian ini adalah teori yang digunakan, yakni 7 kategori teknik propaganda yang dikemukakan oleh Lee\&Lee dan dikembangkan oleh banyak ilmuwan lainnya. Sedangkan perbedaannya adalah sumber data yang diambil. Hasil analisis data menunjukan bahwa mayoritas calon presiden menggunakan strategi testimonial dalam mempropagandakan misi mereka, sedangkan dalam penelitian ini ditemukan bahwa RK lebih banyak menggunakan strategi glittering generality. Hal ini disebabkan karena perbedaan ideologi antara Harian Kompas dan RK. Harian Kompas lebih banyak meminjam tokoh lain untuk memberikan testimoni mengenai penilaiannya terhadap calon presiden sebagai strategi propaganda. Sedangkan RK lebih banyak memuji dan mengangkat objek yang ditemuinya di suatu daerah, kemudian secara tidak langsung memasukan persuasi bahwa objek tersebut sangat sesuai dengan program yang akan ia jalankan jika menjadi pemimpin Jawa Barat.

\section{KESIMPULAN DAN SARAN}

Berdasarkan hasil temuan dan diskusi di atas, maka dapat disimpulkan bahwa Ridwan Kamil sedang berusaha membangun citra positif di mata masyarakat Jawa Barat. Citra pertama yang ingin dibangun oleh Ridwan Kamil dalam caption Instagramnya adalah integritas yang tinggi dan tidak banyak janji, hal ini terlihat dari tuturannya yang lebih banyak menggunakan tuturan assertif dalam melaporkan kegiatannya serta menunjukan sesuatu yang beliau lihat secara faktual. Beliau tidak menjadikan komisif sebagai strategi nomor satu atau dengan mengedepankan janji-janji. Citra kedua yang ingin dibentuk adalah seorang pemimpin yang menghargai dan mengayomi rakyatnya dengan cara mengapresiasi dan memuji setiap daerah beserta potensi yang ada di dalamnya. Hal ini terlihat dari mayoritas maksim kesantunan yang digunakan adalah maksim penghargaan, dengan skala untung/rugi yang lebih tinggi dibandingkan skala yang lain. Dan citra terakhir yang dibangun adalah dengan mempropagandakan bahwa RK adalah seorang pemimpin yang bijaksana dan memiliki cita-cita yang mulia untuk membangun dan memajukan Jawa Barat. Hal ini terlihat dari strategi propaganda yang banyak digunakan RK yakni 
FON ; Jurnal Pendidikan Bahasa dan Sastra Indonesia

Volume 13 Nomor 2 Tahun 2018

glittering generality. Beliau selalu

Kampanye Politik Pemilihan

mengasosiasikan sesuatu yang dekat

dengan keseharian masyarakat dengan

gagasan beliau dalam visi misinya sebagai

kandidat Gubernur Jawa Barat.

Penelitian ini menggunakan pendekatan multi disiplin sebagai pisau analisis data, akan lebih baik jika kedepannya dilakukan penelitian lain menggunakan perspektif linguistik dengan pendekatan interdisiplin yang lebih mendalam dan detail. Selain itu, sangat banyak lahan penelitian di bidang linguistik yang dapat dikembangkan dan diimplementasikan dalam kehidupan sehari-hari, peneliti berharap jika akan lebih banyak lagi penelitian linguistik yang bermanfaat bagi masyarakat kedepannya.

\section{Daftar Pustaka}

Allan, Keith. 2001. Natural Language Semantics.UK: Blackwell Publishers Ltd.

Eriyanto. 2001. Analisis Wacana: Pengantar Analisis Teks Media. Yogyakarta: LKiS

Hardini. J. Isriani. 2013. Analisis Pragmatik Dalam Wacana

Rahardi. R. Kunjana. 2005. Pragmatik: Kesantunan Imperatif Bahasa Indonesia. Jakarta: Erlangga

Rochmawati, Dyah. 2017. Pragmatic and Rhetorical Strategies in the EnglishWritten Jokes.

Indonesian Journal of Applied Linguistics, 7(1), Mei 149-159.

Searle, John. R. 1969. Speech Act: An Essay on the Philosophy of Language. London: Cambridge 
FON ; Jurnal Pendidikan Bahasa dan Sastra Indonesia

Volume 13 Nomor 2 Tahun 2018

Septian, Ryo. 2015. Analisis Tindak Tutur

(Analisis Isi Berita Kampanye

Ilokusi dalam bahasa Iklan

Pemilihan Presiden Tahun 2014

Kampanye Partai Politik pada

Pada Harian Kompas Edisi 4

Pemilu Legislatif tahun 2014 di Juni Sampai 5 Juli 2014). Jurnal Indonesia. Surabaya: UNAIR

Humanity Volume 9, Nomor 2.

Subagyo, P. Ari. 2010. Pragmatik Kritis:

Paduan Pragmatik Dengan Analisis

Wacana Kritis.

http://ejournal.umm.ac.id/index.php/ humanity/article/view/2391 diakses tanggal 01 Juni 2018

Yogyakarta: Universitas Sanatha Van Dijk. 1997.Discourse As Social Dharma

Interaction. London: Sage

Sutanto, M. Himawan. 2014. Propaganda Politik Calon Presiden Republik Indonesia 2014 -2019 